\title{
Quest for Optimal Bonus-Malus in Automobile Insurance in Developing Economies: An Actuarial Perspective
}

\author{
Ade Ibiwoye, I. A. Adeleke \& S. A. Aduloju \\ Department of Actuarial Science \& Insurance, University of Lagos, Nigeria
}

Received: May 24, 2011

Accepted: June 17, 2011

doi:10.5539/ibr.v4n4p74

\begin{abstract}
This paper evaluates the bonus-malus system in practice in the Nigerian motor insurance industry. It would appear that the regulation is a bit fluid so that what actually looks like a bonus-malus system is more like a rule of thumb as operators do not honor the industry agreed tariff. This paper constructs an alternative bonus-malus scale that has reasonable penalties and that is yet commercially feasible. The model can easily be replicated for other developing economies.
\end{abstract}

Keywords: Bonus-Malus system, Markov chains, Risk classification, Motor Insurance, Claims, Rating Introduction

Some of the variables commonly used by insurance companies to divide automobile risks into different homogeneous classes include the policyholder's occupation, age, gender, degree of disability, the type and use of car, and place of garage. Once categorized into different groups, the risks can then be rated a priori using generalized linear models (see Renshaw, 1994; Pinquet, 2000) cited in Brouhns et al (2003). However, there are other important or 'hidden' factors that cannot be taken into account by a priori classification. These include swiftness of reflexes, aggressiveness behind the wheel, or knowledge of Highway Code, all of which have bearing on the frequency and severity of motor insurance claims. The existence of these attitudinal factors renders a priori classification yet heterogeneous despite the use of many classification variables.

Further refinements are therefore required. In that wise it had since occurred to insurance underwriters that the hidden characteristics are partly revealed by the number of claims reported by the policyholders. To allow for this feature an adjustment is often made to the premium of individual policyholders (Henwood and Wang, 2009) in form of a merit-rating technique called bonus malus. According to Lemaire (1998), policyholders from a given risk cell are subdivided into bonus-malus classes, and their claims histories then modify the class upon each renewal. Bonus malus system is normally determined by three elements: the premium scale, the initial class, and the transition rules that determine the transfer from one class to another when the number of claims is known. An insured enters the system in the initial class when he applies for insurance, and throughout the entire driving lifetime, the transition rules are applied upon each renewal to determine the new class.

As Table 1 indicates motor insurance is a very important class in the Non-life business in Nigeria in terms of earned premium income, contributing between 36 and 42 percent between 2003 and 2007.

However, while the gross premium contribution of the motor insurance class is rising the loss ratio has also been rising (see Table 1). Between 2003 and 2007 it has hovered between 23 and 27 percent. This high claims ratio is a clear indication that the Nigerian BMS has not been effective in encouraging careful driving.

An optimal BMS should be efficient and at the same time competitive (Guerreiro and Mexia, 2002), aiming to relate as best as possible the premium paid by the insured to his driving experience. Unfortunately, this does not appear to be the case with the Nigerian system. This study examines the Nigerian BMS, identifies its inherent weaknesses, and attempts to construct a bonus-malus model that more appropriately reflects the need of the market.

The rest of the paper is structured as follows: Section 2 reviews relevant literature. Section 3 reviews the operations of BM premium merit rating in other countries while Section 4 examines the current situation in Nigeria. Model development and risk premium calculation are carried out in Section 5 while Section 6 discusses the results of the model. Section 7 concludes.

\section{Bonus-Malus in Context}

Lemaire (1998) traces the introduction of bonus-malus systems (BMSs) in Europe to the early 1960s following the seminal works of Delaporte (1965), Bichsel (1964), and Buhlmann (1964). Introducing bonus-malus scheme could, in theory, be expected to create more incentives for safe driving, as it links individual premiums to past reported 
accidents. However, in reality, the system appears to mainly encourage non-reporting of claims, especially minor claims, rather than safer driving (Aeron-Thomas, 2002).

Mert and Saykan (2005) argues that since there is no difference between the policyholder having an accident with a small size of loss and a policyholder with a big size of loss, the classical BMS can be said to be unfair. Therefore, an optimal system which takes both the frequency and severity component into account must be used to set the premium an insured will pay.

The complexity of the bonus malus system is probably reflected in the multiplicity of past efforts directed at developing an optimal model. Lemaire (1995), for example, considered as optimal the BMS obtained using the quadratic error loss function, the expected value premium calculation principle and the Negative Binomial as the claim frequency distribution. Similarly, Tremblay (1992) tried to design an optimal BMS using the quadratic error loss function, the zero-utility premium calculation principle and the Poisson- Inverse Gaussian as the claim frequency distribution.

There is also variation across regions. In the UK, the level of highest bonus between 50 to $60 \%$ is reached after 4 to 6 years, making it more of a marketing scheme rather than a way to truly distinguish risk. The effectiveness of BMSs has been doubted, if not rejected, for many years. In contrast, it can take up to 25 years to earn the comparative level of bonus in the German system (Schmitt, 2000). Many of the bonus-malus systems used in North America are based on the posteriori ratemaking mechanisms in which several types of events are taken into consideration. Safe driving is encouraged by rewarding drivers who do not cause an accident, or incur a traffic law violation (Pitrebois, Denuit and Walhin, 2005).

The problem with the BMS in Portugal is that there is no efficient transfer of information between insurers. As a result, there is possible rotation of policyholder which, after making a claim during an insurance period, would leave his insurer and buy another policy from a competitor, thus managing to escape the malus (Guerreiro and Mexia, 2002). In Brazil, motor insurance policyholders are subdivided into seven classes, with premium levels 100, 90, 85, $80,75,70$, and 65 , with new comers joining in class 7 , at level 100 . Each claim-free year results in a one-class discount, and each at-fault claim is penalized by one class. Although it is a very simple system, it is doubtful whether it will be able to effectively motivate safe driving.

In Africa, the Kenya system described as pure by Verico (2002) has seven classes with the merit factors ranging from 1 which is the coefficient for the entry class to 0.4 . The problem with the Kenyan system is that no potential policyholders may expect such a system to be transparent as no provision seems to have been made in the premium construction to accommodate the bonus granted to the good drivers. The weaknesses in the Tunisian system which started in 1992 includes inaccessibility of the private insurers to centralized information on risk classes, underreporting of accidents when there is no injury or death, absence of price competition which may lead to inefficiency, and the reduction of the probability that good risks would be involved in a reported accident, while failing to do that for bad risks (Dionne, 2005).

\section{Current Practice in Nigeria}

The Nigerian BMS, better known in the market as No-Claim-Discount (NCD), officially recognizes three categories of motor vehicles, in line with the provision of the Nigeria Motor Tariff prepared by the Nigerian Insurers Association. The first, shown in Table 2, is for private motor cars.

\section{Insert Table 2 Here}

In this category, a discount may be allowed based on a scale calculated on the net renewal premium in respect of each motor vehicle. Where a policyholder reported no accident during the previous insurance year, he would be given a 20 percent premium discount (bonus) in the current period. Where no accident is reported during the second year, the premium discount (bonus) will be increased to 25 percent. For the third, fourth and fifth claim-free insurance years, the premium discount is 33.3 percent, 40 percent and 50 percent respectively. The premium discount, however, cannot exceed 50 percent, as no discounts are allowed after the fifth claim-free year.

In this system, private car policyholders are grouped into six classes, with premium levels $100,80,75,66.7,60$, and 50 , designated as $\mathrm{C} 0, \mathrm{C} 1, \mathrm{C} 2, \mathrm{C} 3, \mathrm{C} 4$, and $\mathrm{C} 5$ respectively. Where a claim is reported during any of these periods, regardless of the policyholder's risk class, all the discounts will be lost, and the policyholder will start all over from class $\mathrm{C} 0$ where he will pay 100 percent of annual premium. If the policyholder moves to another insurer at the end of a period, he keeps the same class as long as he is able to document his class with the previous insurer. Then, the same rule applies for all subsequent reported accident-free years. The discount is not cumulatively effective and in the event of any claim, the period of classification for discount commences de novo as from the next renewal. This 
means that in whatever class a policyholder is when making a claim, he loses all the bonuses and starts as a new entrant.

The second category consisting of commercial vehicles on schedules 1 to 5 is shown in Table 3 . For this category, a discount of $15 \%$ in premium is allowed where no claim is made or pending during the preceding year or years of insurance.

Insert Table 3 Here

The third category, shown in Table 4 and consisting of Commercial vehicles on schedules 6 , has a discount of 10 percent allowed irrespective of the number of claim-free years.

Insert Table 4 Here

One can observe from the preceding paragraphs that the Nigerian NCD is far from optimal due to a number of weaknesses. First, the official BMS fails to recognize both the frequency and severity of policyholder's claim in its design, thus imposing the same penalty on those who make only one claim during a policy year and those who make several claims, implicitly making assumption that claim frequency and loss severity are independent. Conversely, in the next insurance period, blanket discounts are given to all the policyholders falling within a class who make no claim in the present period, irrespective of the number of claims as well as the size of claims made during the past years.

Second, any claim reported by a policyholder irrespective of his present class and regardless of the level of his accumulated bonuses over the year, will lead to the cancellation of all bonuses in the next insurance period. Third, depreciation of vehicles insured over the years is not accounted for in the computation of final premium after applying the bonus or the malus, as the case may be. Fourth, the transfer of information between insurers is not efficient.

Presently the system allows a policyholder, after a claim experience during an insurance period, to leave his insurer and obtain another cover from a competitor thereby managing to escape the penalty by premium surcharge. Fifth, due to competition, it has been observed that a good number of insurers are not following the laid down procedure in practice. In very many cases, discounts are arbitrarily given to new policyholders, sometimes, up to 65 percent! There have been complaints that rating risks appropriately has been the problem in this market and this has adversely affected the fortunes of the industry (Madiebo, 2002; Versi, 2008).

One of the attributes of the bonus-malus system is its ability to deal with the problem of adverse selection as it is designed to evaluate as faithfully as possible the true distribution of reported accidents. related to unchanging characteristics. Another role is linked to moral hazard and implies that the distribution of reported accidents over time must be taken into account in order to maintain the incentives for cautious behavior at an optimal level (Dionne, 2005). Dionne and Dostie (2007) have shown that such a system can have two effects when the insurance industry is committed to its application. First, it can motivate drivers to be more prudent because past claims are associated with increased insurance premiums in the future (moral hazard). Second, it can improve risk-classification by allowing insurance companies to make a bad risk pay more and a good risk pay less.

It would appear that in Nigeria, the policyholders tend to concentrate on the high discount classes without this tendency being counterbalanced by an adequate scale of merit factors. Oftentimes, the insurers, in order to grant to the large numbers of good drivers the discounts they have promised them, find themselves forced to increase the base premium: in this way, most of the bonus evaporates. The end result is that the yearly mean merit coefficient progressively decreases. This decrease of the mean factor actually determines a transfer of financial weight among the generations of policyholders which is really hard to justify and causes a yearly automatic increase of the premium that, in turn, is very hard to accept by the insureds. A second problem, similar to that observed by Verico (2002), is that, after a claimless year, a policyholder may be asked to pay, at renewal, a higher premium than the one paid in the previous year.

Another side effect of many BMSs currently in use is a tendency of policyholders to pay small claims themselves and not report them to their insurers to avoid future premium increases. In some countries the existence of this phenomenon, called the hunger for bonus, has been explicitly recognized by regulators. In Germany, for instance, the policy wording specifies that, if the insured reimburses the carrier for the cost of the claim, the penalty will not be applied.

\section{Theoretical Background}

Actuaries have come up with a number of mathematical models that would ensure that any BMS adopted by an insurance market is fair to both parties to an insurance contract. Many of the BMS in practice follow a Markov chain 
consisting of a finite number of classes where the premium can be reviewed upward or downward depending on a policyholder's past record of reported accidents and in accordance with transition rules (Brouhns et al., 2003; Denuit and Dhaene, 2000; Lemaire, 1995; and Dionne and Vanasse, 1989). Frangos and Vrontos (2001) explained that a BMS is called optimal if it satisfies two conditions: first, it must be financially balanced for the insurer, that is, the total amount of bonuses is equal to the total amount of maluses, and second, it must be fair to the policyholder, that is, each policyholder pays a premium proportionate to the risk that he brings to the pool.

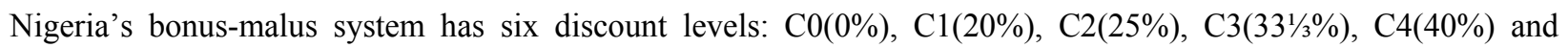
C5(50\%). Movement from discount class $C_{i}$ in one year to discount class $C_{j}$ is a random event with probability $P_{i j}$ which is the same as for all the insured in a specific rating group. We let $P^{0}=\left(p_{1}^{0}, p_{2}^{0}, p_{3}^{0}, p_{4}^{0}, p_{5}^{0}, p_{6}^{0}\right)$ to denote the vector of probabilities with which an individual starts in the various discount levels and the transition probabilities for one year movement within the discount classes as $\varepsilon=\left\{E_{0}, E_{1}, E_{2}, E_{3}, E_{4}, E_{5}\right\}$.

It is further assumed that the movement from class $C_{i}$ in one year to class $C_{j}$ in the following year is independent of how the individual arrived in class $C_{i}$ to begin with. This reflects the memoryless property of Markov chains and the model can therefore be seen as a special case of a Markov process with finite number of states (or classes). Assuming a person initially starts in category $E_{o}$ and that no discount is given initially in year 0 , then as defined in Ibiwoye and Adeleke (2011) we have:

$$
P^{0}=\left(p_{1}^{0}, p_{2}^{0}, p_{3}^{0}, p_{4}^{0}, p_{5}^{0}, p_{6}^{0}\right)=(1,0,0, \ldots, 0)
$$

Similarly, we use $p_{j}^{n+1}$ to denote the probability that an individual is in class $E_{j}$ at time (year) $n+1$. In order to be in class $E_{j}$ at time $n+1$, an individual has to be in some class $E_{i}$ in year $n$ and then pass to $E_{\mathrm{j}}$ in the following year.

We therefore have

$$
P\left(E_{j} \text { in year } n+1\right)=p_{j}^{n+1}=\sum_{i=0}^{k} p_{l}^{n} p_{l j}
$$

This implies

$P^{n+1}=\left(p_{0}^{n}, \ldots, p_{k}^{n}\right) \cdot P=P^{n} \cdot P$

So that

$P^{1}=\left(p_{0}^{1}, \ldots, p_{k}^{1}\right)=\left(p_{0}^{0}, \ldots, p_{k}^{0}\right) \cdot P$

Similarly, given any $n$ and $m$ we can easily show that

$P^{n+m}=\left(p_{0}^{n+m}, \ldots, p_{k}^{n+m}\right)=\left(p_{0}^{n}, \ldots, p_{k}^{n}\right) \cdot P^{m}$

As shown in Ibiwoye and Adeleke (2011) no matter the initial distribution, $\boldsymbol{P}^{\circ}$, for the bonus-malus model, there is a stationary distribution $\pi=\left(\pi_{0}, \pi_{1}, \ldots, \pi_{k}\right)$ to which $\boldsymbol{P}^{n}$ converges as $n$ becomes large. Rather than giving a blanket discount $d_{i}$, we propose the incorporation of the severity into the NCD to take care of the peculiar risk that is associated with the insured $i$. Hence the risk premium should be charged such that it depends on the number of years $y$, that the insured had been under observation and the total number of claims and the magnitude of these claims.

\section{Claim Frequency distribution}

Poisson-exponential mixture

Here, we assume that the number of claims $n$ is Poisson distributed with parameter $\lambda$. This parameter is a measure of risk of each insured. We also assume that $\lambda$ is exponentially distributed with parameter $\beta$. That is, the distribution of $n$ is

$$
f(n / \lambda)=\left\{\begin{array}{lr}
\frac{e^{-\lambda} \lambda^{n}}{n !}, & n=0,1,2, \ldots \\
0 & \text { elsewhere }
\end{array}\right.
$$

The distribution of $\lambda$ is

$$
h(\lambda)=\left\{\begin{array}{lr}
\beta e^{-\lambda \beta}, & \lambda>0 \\
0 & \text { elsewhere }
\end{array}\right.
$$

Using the Bayesian estimation, the unconditional distribution of $n$ claims is obtained as

$$
f(n)=\beta(1+\beta)^{n+1}, \quad n=0,1,2, \ldots
$$

This is geometrically distributed.

Let $n_{\mathrm{y}}$ be the number of claims made by insured $i$ in year $\mathrm{y}, y=1,2,3, \ldots, m$, then the total number of claims an insured had in $m$ years is $N=\sum_{y=1}^{m} n_{y}$.

The conditional distribution of $N=\sum_{y=1}^{m} n_{y}$ claims in $m$ years is 


$$
f\left(n_{1}, n_{2}, \ldots, n_{m} / \lambda\right)=\frac{e^{-\lambda m} \lambda^{N}}{\prod_{y=1}^{m} n_{y} !}
$$

The posterior structure function for a group of insured with claim history $n_{1}, n_{2}, \ldots, n_{m}$ is found as $f\left(\lambda / n_{1}, n_{2}, \ldots, n_{m}\right)=\frac{(t+\beta)^{N+1}}{\Gamma(N+1)} e^{-\lambda(t+\beta)} \lambda^{N}, \lambda>0$

Consequently, using the quadratic loss function, the estimate for the expected number of claims of an insured with claim history $n_{1}, n_{2}, \ldots, n_{m}$ is

$$
\hat{\lambda}_{m+1}=\frac{N+1}{\beta+m}
$$

\section{Poisson-Gamma mixture}

Similarly, consider if we assume that the number of claims $n$ is Poisson distributed with parameter $\lambda$. And hHere, $\lambda$ is assumed to be distributed as gamma with parameters $\alpha$ and $\beta$.

That is, the distribution of $n$ is

$$
f(n / \lambda)=\left\{\begin{array}{lr}
\frac{e^{-\lambda} \lambda^{n}}{n !}, & n=0,1,2, \ldots \\
0 & \text { elsewhere }
\end{array}\right.
$$

The distribution of $\lambda$ is

$$
u(\lambda)=\left\{\begin{array}{cc}
\frac{\lambda^{\alpha-1} \beta^{\alpha} e^{-\beta \lambda}}{\Gamma(\alpha)}, & \alpha>0, \beta>0, \lambda>0 \\
0 & \text { elsewhere }
\end{array}\right.
$$

Using the Bayesian estimation, the unconditional distribution of $n$ claims is obtained as Negative Binomial with parameters $\alpha$ and $\beta$, that is

$$
f(n)=\left(\begin{array}{c}
n+\alpha-1 \\
n
\end{array}\right)\left(\frac{\beta}{1+\beta}\right)^{\alpha}\left(\frac{1}{1+\beta}\right)^{n}, \quad n=0,1,2, \ldots
$$

Consequently, using the quadratic loss function, the estimate for the expected number of claims of an insured with claim history $n_{1}, n_{2}, \ldots, n_{m}$ is

$$
\hat{\lambda}_{m+1}=\frac{N+\alpha}{\beta+m}
$$

\section{Claim Severity distribution}

Regarding claims severity, researchers, especially the actuaries have come up with a number of mathematical models that would ensure that any BMS adopted by an insurance market is fair to both parties to an insurance contract. As noted earlier, a BMS is called optimal if it satisfies two conditions: first, it must be financially balanced for the insurer, that is, the total amount of bonuses is equal to the total amount of maluses, and second, it must be fair to the policyholders, that is, each policyholder pays a premium proportionate to the risk that he brings to the pool (Frangos and Vrontos, 2001). Where there is no difference in penalty between the policyholder having an accident with a small size of loss and a policyholder with a big size of loss, a BMS can be said to be unfair. Therefore, an optimal system which takes both the frequency and severity component into account must be used to set the premium an insured will pay (Mert and Saykan, 2005).

We now look at the severities. Many claim (high and small) severities are observed in motor insurance. Given that $c$ is the claim size made by each insured with unequal mean size $\lambda$ inverse gamma with parameters $\alpha$ and $\beta$ defined by

$$
h(\lambda)= \begin{cases}\frac{\frac{1}{\beta} e^{-\frac{\beta}{\lambda}}}{\left(\frac{\lambda}{\beta}\right)^{\alpha+1} \Gamma(\alpha)}, & \alpha>0, \beta>0, \lambda>0 \\ 0 & \text { elsewhere }\end{cases}
$$

Using the Bayesian estimation, the unconditional distribution of claim size $c$, is obtained as Pareto with parameters $\alpha$ and $\beta$ (see Hogg, McKeen and Craig, 2005), and using the quadratic loss function, the estimate for the expected claim amount of an insured with claim size history $c_{1}, c_{2}, \ldots, c_{m}$ is

$$
\hat{\lambda}_{m+1}=\frac{\beta+M}{\alpha+N-1}
$$


where $M=\sum_{y=1}^{m} c_{y}$

\section{Risk Premium Calculation}

Given that the premium charged for a particular motor insurance is $P$ then, the risk premium for an insured putting frequency and severity into consideration is

Case 1: Using number of claims only

Poisson-exponential mixture

$$
\text { Risk premium at time } m+1=P \times \frac{N+1}{\beta+m}
$$

Poisson-Gamma mixture

$$
\text { Risk premium at time } m+1=P \times \frac{N+\alpha}{\beta+m}
$$

Case 2: Using frequency and severity

Poisson-exponential mixture with exponential-inverse gamma

$$
\text { Risk premium at time } m+1=P \times \frac{N+1}{\beta+m} \times \frac{\beta+M}{\alpha+N-1}
$$

Poisson-Gamma mixture with exponential-inverse gamma

$$
\text { Risk premium at time } m+1=P \times \frac{N+\alpha}{\beta+m} \times \frac{\beta+M}{\alpha+N-1}
$$

Case 3: Factoring depreciation rate of vehicles without severity

Poisson-exponential mixture

$$
\text { Risk premium at time } m+1=P \times \frac{N+1}{\beta+m} \times d^{m}
$$

where $d$ is the depreciation rate which is always assumed to be $10 \%$

Poisson-Gamma mixture

$$
\text { Risk premium at time } m+1=P \times \frac{N+\alpha}{\beta+m} \times d^{m}
$$

Case 4: Using frequency and severity

Poisson-exponential mixture with exponential-inverse gamma

$$
\text { Risk premium at time } m+1=P \times \frac{N+1}{\beta+m} \times \frac{\beta+M}{\alpha+N-1} \times d^{m}
$$

Poisson-Gamma mixture with exponential-inverse gamma

$$
\text { Risk premium at time } m+1=P \times \frac{N+\alpha}{\beta+m} \times \frac{\beta+M}{\alpha+N-1} \times d^{m}
$$

The results are displayed in Appendices I - IV

\section{Discussion of Results}

Unlike the existing practice where a discount of 20 percent is given in the first year to a policyholder who has no claim, our model rewards a policyholder without a claim after the first policy year with a premium discount of 44 percent. Although this may raise concern about profitability it is known that competition already makes this the actual practice in Nigeria. If one claim is recorded after one year, the policyholder is penalized with an increase in premium of about 11.11 percent. If two claims are made the penalty increases to 22.22 percent and so on. The existing method does not recognize the number of previous claims but simply returns the insured to the initial state.

Another uniqueness of the model is that it recognizes longevity of safe driving. Whereas in the existing system there is no further incentive after a period of five years other than the 50 percent discount in premium for a careful driver who presents no claim our model extends the incentive to ten years. A policy holder who reports no claim in ten years can expect to get a discount as high as 90 percent of initial premium. On the other hand if within the first year of the contract the policy holder makes as many as five claims then the penalty for the next policy year can rise as high as 300 percent of initial premium. Thus, instead of moving up and down a 'fixed ladder' of premium rates, our model encourages premium assessment based on the claims history of the policyholder.

\section{Conclusion}

The study observes many lapses in the existing BMS that make it ineffective as a deterrent to careless drivers. The model we have developed takes into account the frequency and severity of loss. This serves as an incentive for road 
safety. To still further improve on the system the regulatory authorities should organize a data bank which would help each insurance company to have better access to the past record of claims at fault.

\section{References}

Aeron-Thomas, A. (2002). The role of the motor insurance industry in preventing and compensating road casualties, Scoping Study Final Report, www.dfid.gov.uk/r4d/pdf/outputs/R8012.pdf . Accessed January 5, 2011.

Babington-Ashaye, F. (2008). Refocusing the insurance industry towards FSS 2020. http://www.riskanalyst-ng.com BGL (2010) BGL Insurance Report 2010: Promise kept or promise deferred. www.bglplc.com accessed 28/01/2011

Brouhns, N., M. Guillen, M. Denuit, and J. Pinquet. (2003). Bonus-malus scales in segmented tariffs with stochastic migration between segments, Journal of Risk and Insurance, vol. 70 (4) pp. 577-599, http://dx.doi.org/10.1046/j.0022-4367.2003.00066.x

CEA. (2007). The European motor insurance market. CEA Statistics $N^{\circ} 32$ December 2007

Coene, G. and Doray, L.G. (1996). A financially balanced bonus-malus system. ASTIN Bulletin. Vol. 26, No.1. pp 107-116, http://dx.doi.org/10.2143/AST.26.1.563236

Denuit, M. and Dhaene, J. (2000). Bonus-malus scales using exponential loss functions, Bulletin of German Society of Actuaries, 25, pp. 13-27.

Dionne, G., R. Gagne, and C. Vanasse. (1998). Inferring technological parameters from incomplete panel data, Journal of Econometrics, vol.87, pp.303-327, http://dx.doi.org/10.1016/S0304-4076(98)00002-5

Dionne, G. (2005). The (1992) bonus-malus system in Tunisia: an empirical evaluation. The Journal of Risk and Insurance, Vol. 72, No. 4, pp. 609-633, doi:10.1111/j.1539-6975.2005.00141.x, http://dx.doi.org/10.1111/j.1539-6975.2005.00141.x

Dionne, G. and Dostie, B. (2007). Estimating the effect of a change in insurance pricing regime on accidents with

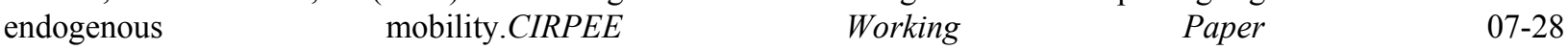
www.cirpee.org/fileadmin/documents/Cahiers_2007/CIRPEE07-28.

Frangos, N. E., and Vrontos, S. D. (2001). Design of optimal bonus-malus systems with a frequency and a severity component on an individual basis in automobile insurance. ASTIN BULLETIN, Vol. 31, No. 1, pp. 1-22, http://dx.doi.org/10.2143/AST.31.1.991

Guerreiro, G. and Mexia, J. (2002). An alternative approach to bonus malus, http://pascal.iseg.utl.pt/ cemapre/ime2002/main_page/abstracts/RitaGuerreiro.pdf

Harlaar, H. (2008). Introduction of the no-claim protector: research of the consequences for the Dutch car insurance market AENORM, 58 (Jan)

Henwood, N., and Wang, B. (2009). Insights into comprehensive motor insurance rating. Presented to the Institute of Actuaries of Australia 2009 Biennial Convention, 19-22 April

Holtan, J. (1999). Optimal insurance coverage under bonus-malus contracts. Paper to be presented at the 30th International ASTIN Colloquium, Tokyo, Japan, 22 - 25 August.

Huang, R. J., Tzeng, L. Y., Wang, J. L. \& Wang, K. C. (2006). Evidence for Adverse Selection in the Automobile Insurance Market. www.aria.org/meetings/2006papers/HuangTzengWangWang.pdf.

Lemaire, J. (1995). Bonus-Malus Systems in Automobile Insurance, Kluwer Academic Publishers, Massachusetts.

Lemaire, J. (1998). Bonus-malus systems: the European and Asian approach to merit-rating. North American Actuarial Journal, Vol.2, No.1 (January).

Madiebo, R.I. (2002). Awareness seminar on fidelity guarantee and money insurance rates for banks, presented at a seminar organized by the Nigerian Insurers Association, Lagos, Nigeria, on Friday 31, 2002.

Mert, M and Saykan, Y. (2005). On a bonus malus system where the claim frequency distribution is geometric and the claim severity distribution is pareto Hacettepe Journal of Mathematics and Statistics, Vol. 34, pp.75-81

Neeb, M. (2008), Bonus-malus systems in motor insurance. www.yasni.com/michael+neeb/check+people/ berlin - United States

Nigerian Insurers Association (2010). 2009 Nigeria insurance digest, pp. 51-52. www.nigeriainsures.com .

Nigerian Insurers Association (2009). 2008 Nigeria insurance digest. http://www.capacitysearchgroup.com /2008nigeriainsurancedigest.pdf.

Pinquet, J. (1998). Designing optimal bonus malus systems from different types of claims. ASTIN Bulletin, Vol. 28. No. 2, pp. 205-220, doi:10.2143/AST.28.2.519066, http://dx.doi.org/10.2143/AST.28.2.519066 
Pinquet, J. (2000). Experience rating through heterogeneous models, in: G. Dionne, ed., Handbook of Insurance. Amsterdam. Kluwer Academic Publishers, http://dx.doi.org/10.1007/978-94-010-0642-2_14.

Pitrebois, S, Denuit, M., and Walhin, J. (2006). An actuarial analysis of the French bonus-malus system, Scandinavian Actuarial Journal, Vol. 5, pp.247-264, http://dx.doi.org/10.1080/03461230600986136

Pitrebois, S, Denuit, M., and Walhin, J. (2003). Marketing and bonus-malus Systems. ASTIN (August 24-27), Berlin.

Pitrebois, S, Denuit, M. and Walhin, J. (2005). Multi-event bonus-malus scales. http://www.secura-re.com/secura/pdf/withpeer/Walhin\%5B34\%5D.pdf

Renshaw, A. E., (1994). Modelling the claim process in the presence of covariates, ASTIN Bulletin, 24: 265-285, http://dx.doi.org/10.2143/AST.24.2.2005070

Schmitt, K. E. (2000). European auto insurance pricing considerations. Casualty Actuarial Society Forum, Winter, pp.141-158

Taylor, G. (1997). Setting a bonus-malus scale in the presence of other rating factors. Astin Bulletin, Vol. 27, pp.319-327, http://dx.doi.org/10.2143/AST.27.2.542055

Tremblay, L. (1992). Using the Poisson inverse Gaussian in bonus-malus systems, Astin Bulletin Vol.22, pp.97-106, http://dx.doi.org/10.2143/AST.22.1.2005129

Venter, G.G. (1991). A comparative analysis of most European and Japanese bonus malus systems: extensions. The Journal of Risk and Insurance. http://www.jstor.org/action/showPublisher?publisher Code=ari.

Verico, P. (2002). Bonus-malus systems: lack of transparency and adequate measure. ASTIN Bulleting Vol. 32, No. 2, pp. 315-318, , http://dx.doi.org/10.2143/AST.32.2.1032.NIA (2009). 2008 Nigeria insurance digest. http://www.capacitysearchgroup.com/2008nigeriainsurancedigest.pdf

Versi, A. (2008). Nigeria insurance's gold lined future, African Business, May 2008, http//findarticles.com/p/articles/mi_qa5327/is-200805.

Table1. Loss Ratio of Non Life Insurance in Nigeria (2003-2007) in Nigerian Naira ('000)

\begin{tabular}{|c|c|c|c|c|c|}
\hline CLASS & 2003 & 2004 & 2005 & 2006 & 2007 \\
\hline FIRE & $\begin{array}{l}\text { Prem }=3,412,106 \text { Claim }=1,178,695 \\
\text { Loss ratio } 34.54 \%\end{array}$ & $\begin{array}{l}\text { Prem }=3,789,913 \\
\text { Claim }=1,073,203 \\
\text { Loss ratio } 28.32 \%\end{array}$ & $\begin{array}{l}\text { Prem }=5,947,749 \\
\text { Claim }=1,353,264 \\
\text { Loss ratio } 22.75 \%\end{array}$ & $\begin{array}{l}\text { Prem }=6,017,961 \\
\text { Claim }=2,185,763 \\
\text { Loss ratio } 36.32 \%\end{array}$ & $\begin{array}{l}\text { Prem }=7,242,021 \\
\text { Claim }=1,255,621 \\
\text { Loss ratio } 17.34 \%\end{array}$ \\
\hline MOTOR & $\begin{array}{l}\text { Prem }=11,188,882 \\
\text { Claim }=2,668,506 \\
\text { Loss ratio } 23.85 \%\end{array}$ & $\begin{array}{l}\text { Prem }=12,821,427 \\
\text { Claim }=3,187,384 \\
\text { Loss ratio } 24.86 \%\end{array}$ & $\begin{array}{l}\text { Prem }=14,752,419 \\
\text { Claim=3,582,545 } \\
\text { Loss ratio } 24.28 \%\end{array}$ & $\begin{array}{l}\text { Prem }=14,204,694 \\
\text { Claim }=3,481,840 \\
\text { Loss ratio } 24.51 \%\end{array}$ & $\begin{array}{l}\text { Prem }=22,194,413 \\
\text { Claim }=5,968,138 \\
\text { Loss ratio } 26.89 \%\end{array}$ \\
\hline GEN. ACCID. & $\begin{array}{l}\text { Prem }=4,646,470 \\
\text { Claim }=2,121,426 \\
\text { Loss ratio } 45.66 \%\end{array}$ & $\begin{array}{l}\text { Prem }=6,817,844 \\
\text { Claim }=1,842,906 \\
\text { Loss ratio } 27.03 \%\end{array}$ & $\begin{array}{l}\text { Prem }=8,852,889 \\
\text { Claim }=2,346,753 \\
\text { Loss ratio } 26.51 \%\end{array}$ & $\begin{array}{l}\text { Prem }=10,381,031 \\
\text { Claim }=2,593,799 \\
\text { Loss ratio } 24.99 \%\end{array}$ & $\begin{array}{l}\text { Prem }=12,992,490 \\
\text { Claim }=2,994,047 \\
\text { Loss ratio } 23.04 \%\end{array}$ \\
\hline MARINE & $\begin{array}{l}\text { Prem }=4,342,058 \\
\text { Claim }=1,164,297 \\
\text { Loss ratio } 26.81 \%\end{array}$ & $\begin{array}{l}\text { Prem }=7,389,501 \\
\text { Claim }=1,034,305 \\
\text { Loss ratio } 14.00 \%\end{array}$ & $\begin{array}{l}\text { Prem=7,403,364 } \\
\text { Claim=1,537,448 } \\
\text { Loss ratio } 20.77 \%\end{array}$ & $\begin{array}{l}\text { Prem }=4,944,376 \\
\text { Claim }=839,045 \\
\text { Loss ratio } 16.97 \%\end{array}$ & $\begin{array}{l}\text { Prem }=8,988,165 \\
\text { Claim }=1,139,407 \\
\text { Loss ratio } 12.63 \%\end{array}$ \\
\hline WKM. COMP & $\begin{array}{l}\text { Prem }=882,449 \\
\text { Claim }=357,492 \\
\text { Loss ratio } 40.51 \%\end{array}$ & $\begin{array}{l}\text { Prem }=507,133 \\
\text { Claim }=120,547 \\
\text { Loss ratio } 23.77 \%\end{array}$ & $\begin{array}{l}\text { Prem }=774,732 \\
\text { Claim }=244,878 \\
\text { Loss ratio } 31.61 \%\end{array}$ & $\begin{array}{l}\text { Prem }=535,887 \\
\text { Claim }=132,997 \\
\text { Loss ratio } 24.82 \%\end{array}$ & $\begin{array}{l}\text { Prem }=780,645 \\
\text { Claim }=178,600 \\
\text { Loss ratio } 22.88 \%\end{array}$ \\
\hline OIL/GAS & - & - & - & $\begin{array}{l}\text { Prem }=1,815,662 \\
\text { Claim }=210,240 \\
\text { Loss ratio } 11.58 \%\end{array}$ & $\begin{array}{l}\text { Prem }=2,714,899 \\
\text { Claim }=588,867 \\
\text { Loss ratio } 21.69 \%\end{array}$ \\
\hline MISC & $\begin{array}{l}\text { Prem }=1,626,553 \\
\text { Claim }=418,142 \\
\text { Loss ratio } 25.71 \%\end{array}$ & $\begin{array}{l}\text { Prem }=2,155,740 \\
\text { Claim }=748,787 \\
\text { Loss ratio } 34.73 \%\end{array}$ & $\begin{array}{l}\text { Prem }=3,278,690 \\
\text { Claim }=1,098,975 \\
\text { Loss ratio } 33.52 \%\end{array}$ & $\begin{array}{l}\text { Prem }=3,498,421 \\
\text { Claim }=1,453,286 \\
\text { Loss ratio } 41.54 \%\end{array}$ & $\begin{array}{l}\text { Prem }=6,153,839 \\
\text { Claim }=1,819,644 \\
\text { Loss ratio } 22.83 \%\end{array}$ \\
\hline TOTAL & $\begin{array}{l}\text { Prem }=26,098,518 \\
\text { Claim }=7,908,558\end{array}$ & $\begin{array}{l}\text { Prem }=33,481,558 \\
\text { Claim }=8,007,132\end{array}$ & $\begin{array}{l}\text { Prem }=41,009,853 \\
\text { Claim }=10,163,863\end{array}$ & $\begin{array}{l}\text { Prem }=41,398,032 \\
\text { Claim }=10,686,730\end{array}$ & $\begin{array}{l}\text { Prem }=61,066,481 \\
\text { Claim }=13,944,324\end{array}$ \\
\hline
\end{tabular}

Source: 2008 Nigeria Insurance Digest 
Table 2. Private Motor Car Tariff

\begin{tabular}{|l|l|l|l|l|l|l|}
\hline NCD class & $\mathrm{C} 0$ & $\mathrm{C} 1$ & $\mathrm{C} 2$ & $\mathrm{C} 3$ & $\mathrm{C} 4$ & $\mathrm{C} 5$ \\
\hline$\%$ discount & 0 & 20 & 25 & $33^{1 / 3}$ & 40 & 50 \\
\hline$\%$ pure premium & 100 & 80 & 75 & $662 / 3$ & 60 & 50 \\
\hline
\end{tabular}

Table 3. Commercial Vehicles Tariff (Sch.1-5)

\begin{tabular}{|l|l|l|}
\hline NCD class & C0 & C1 \\
\hline$\%$ discount & 0 & 15 \\
\hline$\%$ pure premium & 100 & 85 \\
\hline
\end{tabular}

Table 4. Commercial vehicles (Sch. 6)

\begin{tabular}{|l|l|l|}
\hline NCD class & C0 & C1 \\
\hline$\%$ discount & 0 & 10 \\
\hline$\%$ pure premium & 100 & 90 \\
\hline
\end{tabular}

Risk Premium Tables

Appendix I: Poisson - exponential

\begin{tabular}{|rccccccccccc|}
\hline & \multicolumn{1}{c}{ number of claims } & \multicolumn{3}{c|}{ Premium $=100,000$} & \multicolumn{5}{c|}{ beta $=0.8$} \\
\hline year & 0 & 1 & 2 & 3 & 4 & 5 & 6 & 7 & 8 & 9 \\
\hline 0 & 125000.00 & & & & & & & & & & \\
1 & 55555.56 & 111111.11 & 166666.67 & 222222.22 & 277777.78 & 333333.33 & 388888.89 & 444444.44 & 500000.00 & 555555.56 & 611111.11 \\
2 & 35714.29 & 71428.57 & 107142.86 & 142857.14 & 178571.43 & 214285.71 & 250000.00 & 285714.29 & 321428.57 & 357142.86 & 392857.14 \\
3 & 26315.79 & 52631.58 & 78947.37 & 105263.16 & 131578.95 & 157894.74 & 184210.53 & 210526.32 & 236842.11 & 263157.89 & 289473.68 \\
4 & 20833.33 & 41666.67 & 62500.00 & 83333.33 & 104166.67 & 125000.00 & 145833.33 & 166666.67 & 187500.00 & 208333.33 & 229166.67 \\
5 & 17241.38 & 34482.76 & 51724.14 & 68965.52 & 86206.90 & 103448.28 & 120689.66 & 137931.03 & 155172.41 & 172413.79 & 189655.17 \\
6 & 14705.88 & 29411.76 & 44117.65 & 58823.53 & 73529.41 & 88235.29 & 102941.18 & 117647.06 & 132352.94 & 147058.82 & 161764.71 \\
7 & 12820.51 & 25641.03 & 38461.54 & 51282.05 & 64102.56 & 76923.08 & 89743.59 & 102564.10 & 115384.62 & 128205.13 & 141025.64 \\
8 & 11363.64 & 22727.27 & 34090.91 & 45454.55 & 56818.18 & 68181.82 & 79545.45 & 90909.09 & 102272.73 & 113636.36 & 125000.00 \\
9 & 10204.08 & 20408.16 & 30612.24 & 40816.33 & 51020.41 & 61224.49 & 71428.57 & 81632.65 & 91836.73 & 102040.82 & 112244.90 \\
10 & 9259.26 & 18518.52 & 27777.78 & 37037.04 & 46296.30 & 55555.56 & 64814.81 & 74074.07 & 83333.33 & 92592.59 & 101851.85 \\
\hline
\end{tabular}

Appendix II: Gamma - exponential

\begin{tabular}{|c|c|c|c|c|c|c|c|c|c|c|c|}
\hline \multirow[b]{2}{*}{ year } & \multirow[b]{2}{*}{0} & \multirow[b]{2}{*}{1} & \multirow[b]{2}{*}{2} & \multicolumn{2}{|c|}{ number of claims } & \multicolumn{3}{|c|}{ Premium $=100,000$} & \multirow{2}{*}{$\begin{array}{c}\text { beta }=0.8 \\
8\end{array}$} & \multicolumn{2}{|l|}{ alfa $=5$} \\
\hline & & & & 3 & 4 & 5 & 6 & 7 & & 9 & 10 \\
\hline 0 & 250000.00 & & & & & & & & & & \\
\hline 1 & 111111.11 & 166666.67 & 222222.22 & 277777.78 & 333333.33 & 388888.89 & 444444.44 & 500000.00 & 555555.56 & 611111.11 & 666666.67 \\
\hline 2 & 71428.57 & 107142.86 & 142857.14 & 178571.43 & 214285.71 & 250000.00 & 285714.29 & 321428.57 & 357142.86 & 392857.14 & 428571.43 \\
\hline 3 & 52631.58 & 78947.37 & 105263.16 & 131578.95 & 157894.74 & 184210.53 & 210526.32 & 236842.11 & 263157.89 & 289473.68 & 315789.47 \\
\hline 4 & 41666.67 & 62500.00 & 83333.33 & 104166.67 & 125000.00 & 145833.33 & 166666.67 & 187500.00 & 208333.33 & 229166.67 & 250000.00 \\
\hline 5 & 34482.76 & 51724.14 & 68965.52 & 86206.90 & 103448.28 & 120689.66 & 137931.03 & 155172.41 & 172413.79 & 189655.17 & 206896.55 \\
\hline 6 & 29411.76 & 44117.65 & 58823.53 & 73529.41 & 88235.29 & 102941.18 & 117647.06 & 132352.94 & 147058.82 & 161764.71 & 176470.59 \\
\hline 7 & 25641.03 & 38461.54 & 51282.05 & 64102.56 & 76923.08 & 89743.59 & 102564.10 & 115384.62 & 128205.13 & 141025.64 & 153846.15 \\
\hline 8 & 22727.27 & 34090.91 & 45454.55 & 56818.18 & 68181.82 & 79545.45 & 90909.09 & 102272.73 & 113636.36 & 125000.00 & 136363.64 \\
\hline 9 & 20408.16 & 30612.24 & 40816.33 & 51020.41 & 61224.49 & 71428.57 & 81632.65 & 91836.73 & 102040.82 & 112244.90 & 122448.98 \\
\hline 10 & 18518.52 & 27777.78 & 37037.04 & 46296.30 & 55555.56 & 64814.81 & 74074.07 & 83333.33 & 92592.59 & 101851.85 & 111111.11 \\
\hline
\end{tabular}


Risk Premium Tables allowing for depreciation

Appendix III: Poisson - exponential

\begin{tabular}{|rccccccccccc|}
\hline & \multicolumn{1}{c}{ number of claims } & \multicolumn{3}{c|}{ Premium $=100,000$} & \multicolumn{3}{c|}{ beta $=0.8$} \\
\hline year & 0 & 1 & 2 & 3 & 4 & 5 & 6 & 7 & 8 & 9 \\
\hline 0 & 125000.00 & & & & & & & & & & \\
1 & 55555.56 & 100000.00 & 135000.00 & 162000.00 & 182250.00 & 196830.00 & 206671.50 & 212576.40 & 215233.61 & 215233.61 & 213081.27 \\
2 & 35714.29 & 64285.71 & 86785.71 & 104142.86 & 117160.71 & 126533.57 & 132860.25 & 136656.26 & 138364.46 & 138364.46 & 136980.82 \\
3 & 26315.79 & 47368.42 & 63947.37 & 76736.84 & 86328.95 & 93235.26 & 97897.03 & 100694.08 & 101952.76 & 101952.76 & 100933.23 \\
4 & 20833.33 & 37500.00 & 50625.00 & 60750.00 & 68343.75 & 73811.25 & 77501.81 & 79716.15 & 80712.60 & 80712.60 & 79905.48 \\
5 & 17241.38 & 31034.48 & 41896.55 & 50275.86 & 56560.34 & 61085.17 & 64139.43 & 65971.99 & 66796.64 & 66796.64 & 66128.67 \\
6 & 14705.88 & 26470.59 & 35735.29 & 42882.35 & 48242.65 & 52102.06 & 54707.16 & 56270.22 & 56973.60 & 56973.60 & 56403.87 \\
7 & 12820.51 & 23076.92 & 31153.85 & 37384.62 & 42057.69 & 45422.31 & 47693.42 & 49056.09 & 49669.29 & 49669.29 & 49172.60 \\
8 & 11363.64 & 20454.55 & 27613.64 & 33136.36 & 37278.41 & 40260.68 & 42273.72 & 43481.54 & 44025.06 & 44025.06 & 43584.81 \\
9 & 10204.08 & 18367.35 & 24795.92 & 29755.10 & 33474.49 & 36152.45 & 37960.07 & 39044.64 & 39532.70 & 39532.70 & 39137.38 \\
10 & 9259.26 & 16666.67 & 22500.00 & 27000.00 & 30375.00 & 32805.00 & 34445.25 & 35429.40 & 35872.27 & 35872.27 & 35513.54 \\
\hline
\end{tabular}

Appendix IV: Gamma - exponential

\begin{tabular}{|c|c|c|c|c|c|c|c|c|c|c|c|}
\hline \multirow[b]{2}{*}{ year } & \multirow[b]{2}{*}{0} & \multirow[b]{2}{*}{1} & \multicolumn{3}{|c|}{ number of claims } & \multicolumn{2}{|c|}{ Premium $=100,000$} & \multicolumn{2}{|r|}{ beta $=0.8$} & \multicolumn{2}{|l|}{ alpha $=5$} \\
\hline & & & 2 & 3 & 4 & 5 & 6 & 7 & 8 & 9 & 10 \\
\hline 0 & 250000.00 & & & & & & & & & & \\
\hline 1 & 111111.11 & 150000.00 & 180000.00 & 202500.00 & 218700.00 & 229635.00 & 236196.00 & 239148.45 & 239148.45 & 236756.97 & 232452.29 \\
\hline 2 & 71428.57 & 96428.57 & 115714.29 & 130178.57 & 140592.86 & 147622.50 & 151840.29 & 153738.29 & 153738.29 & 152200.91 & 149433.62 \\
\hline 3 & 52631.58 & 71052.63 & 85263.16 & 95921.05 & 103594.74 & 108774.47 & 111882.32 & 113280.84 & 113280.84 & 112148.04 & 110108.98 \\
\hline 4 & 41666.67 & 56250.00 & 67500.00 & 75937.50 & 82012.50 & 86113.13 & 88573.50 & 89680.67 & 89680.67 & 88783.86 & 87169.61 \\
\hline 5 & 34482.76 & 46551.72 & 55862.07 & 62844.83 & 67872.41 & 71266.03 & 73302.21 & 74218.48 & 74218.48 & 73476.30 & 72140.37 \\
\hline 6 & 29411.76 & 39705.88 & 47647.06 & 53602.94 & 57891.18 & 60785.74 & 62522.47 & 63304.00 & 63304.00 & 62670.96 & 61531.49 \\
\hline 7 & 25641.03 & 34615.38 & 41538.46 & 46730.77 & 50469.23 & 52992.69 & 54506.77 & 55188.10 & 55188.10 & 54636.22 & 53642.84 \\
\hline 8 & 22727.27 & 30681.82 & 36818.18 & 41420.45 & 44734.09 & 46970.80 & 48312.82 & 48916.73 & 48916.73 & 48427.56 & 47547.06 \\
\hline 9 & 20408.16 & 27551.02 & 33061.22 & 37193.88 & 40169.39 & 42177.86 & 43382.94 & 43925.23 & 43925.23 & 43485.97 & 42695.32 \\
\hline 10 & 18518.52 & 25000.00 & 30000.00 & 33750.00 & 36450.00 & 38272.50 & 39366.00 & 39858.08 & 39858.08 & 39459.49 & 38742.05 \\
\hline
\end{tabular}

